\title{
How does the health and well-being of young Australian vegetarian and semi-vegetarian women compare with non-vegetarians?
}

\author{
Surinder Baines ${ }^{1, *}$, Jennifer Powers ${ }^{2}$ and Wendy J Brown ${ }^{3}$ \\ ${ }^{1}$ School of Health Sciences, Nutrition and Dietetics, Box 38, Hunter Building, University of Newcastle, \\ Callaghan, New South Wales 2308, Australia: ${ }^{2}$ Research Centre for Gender and Health, University of Newcastle, \\ Newcastle, New South Wales, Australia: ${ }^{3}$ School of Human Movement Studies, University of Queensland, St Lucia, \\ Queensland, Australia
}

Submitted 5 January 2005: Accepted 13 February 2006

\begin{abstract}
Objective: To compare the sociodemographic characteristics, health status and health service use of vegetarians, semi-vegetarians and non-vegetarians.

Design: In cross-sectional data analyses of the Australian Longitudinal Study on Women's Health in 2000, 9113 women (aged 22-27 years) were defined as nonvegetarians if they reported including red meat in their diet, as semi-vegetarians if they excluded red meat and as vegetarians if they excluded meat, poultry and fish from their diet.

Results: The estimated prevalence was 3\% and 10\% for vegetarian and semi-vegetarian young women. Compared with non-vegetarians, vegetarians and semi-vegetarians were more likely to live in urban areas and to not be married. Vegetarians and semivegetarians had lower body mass index (mean (95\% confidence interval): 22.2 (21.722.7) and $23.0(22.7-23.3) \mathrm{kg} \mathrm{m}^{-2}$ ) than non-vegetarians (23.7 (23.6-23.8) $\mathrm{kg} \mathrm{m}^{-2}$ ) and tended to exercise more. Semi-vegetarians and vegetarians had poorer mental health, with $21-22 \%$ reporting depression compared with $15 \%$ of non-vegetarians $(P<0.001)$. Low iron levels and menstrual symptoms were also more common in both vegetarian groups. Vegetarian and semi-vegetarian women were more likely to consult alternative health practitioners and semi-vegetarians reported taking more prescription and non-prescription medications. Compared with non-vegetarians, semi-vegetarians were less likely and vegetarians much less likely to be taking the oral contraceptive pill.

Conclusion: The levels of physical activity and body mass indices of the vegetarian and semi-vegetarian women suggest they are healthier than non-vegetarians. However, the greater reports of menstrual problems and the poorer mental health of these young women may be of clinical significance.
\end{abstract}

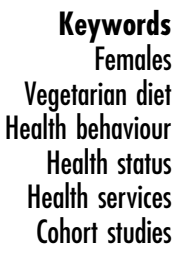

Much of the literature about the health of vegetarians is contradictory. Although many studies have reported health benefits of vegetarian diets ${ }^{1-5}$, more recent studies of adolescents suggest vegetarians have poorer health ${ }^{6-8}$. Some of this variation in health benefits may be due to differences between studies in the definition of 'vegetarian', sampling strategies and the age of participants. First, the term 'vegetarian' has been used to describe a whole range of diets from the avoidance of red meat (sometimes referred to as semi-, pseudo- or partial vegetarian) and the exclusion of meat, poultry and fish (vegetarian) to the exclusion of all foods of animal origin (vegan) $)^{8,9}$. Second, many of the studies of the effects of vegetarian diets have been restricted to specific groups such as Seventh Day Adventists, or members of vegetarian societies and customers of health food shops ${ }^{4,5}$. Finally, studies of older adults have tended to show health benefits of vegetarian-style diets whereas those of younger people have not ${ }^{2,6,8}$.

In terms of health behaviours, several studies of vegetarian and non-vegetarian adolescents have found little difference in smoking status, alcohol use and physical activity $^{6,7,9,10}$. Others have found higher levels of physical activity and lower body mass index (BMI) among vegetarians, with vegans having the lowest $\mathrm{BMI}^{1,11,12}$. In other studies, the lower alcohol and tobacco consumption reported by vegetarians may be due to sample selection rather than vegetarian status ${ }^{4,13,14}$.

Relatively little information is available concerning morbidity in vegetarians ${ }^{1}$. Several studies have identified low iron and related symptoms in vegetarians and meat avoiders $^{15}$. One large Scandinavian study $(n=2041)$ has confirmed higher levels of symptoms such as depression, 
tiredness and headaches among low meat consumers ${ }^{6}$, and smaller studies have identified menstrual irregularity among vegetarian women ${ }^{16-18}$. Others have found that adolescent vegetarians were more likely to attempt selfharm than non-vegetarians ${ }^{8}$. Several studies have reported lower use of prescription medications and health services by vegetarians ${ }^{13,14,19}$

The overall picture of the health of vegetarians therefore appears to be mixed, with some studies reporting better health and others reporting poorer health among vegetarians. In light of the apparent increase in the number of young people choosing a vegetarian-style diet $^{6,8,20}$ and the higher prevalence of vegetarianism among younger people and women ${ }^{20,21}$, there is a need to investigate the health and lifestyle of young vegetarian and non-vegetarian women in the broader community. The aim of the present paper was therefore to explore differences in sociodemographic characteristics, health status and health service use in a representative sample of young Australian women who were defined as vegetarian, semi-vegetarian and non-vegetarian.

\section{Methods}

\section{Sample}

The Australian Longitudinal Study on Women's Health (ALSWH) is a large national study that is designed to investigate the health and well-being of women over a 20year period $^{22}$. Women were randomly selected from the national health insurance database (Medicare) that includes almost all permanent residents of Australia, with over-representation of women living in rural and remote areas. Over 40000 women in three cohorts ('younger', 1823 years; 'mid aged', 45-50 years; and 'older', 70-75 years) completed the first survey in 1996. A comparison with the 1996 Census showed that the respondents were largely representative of women in the same age groups, with some over-representation of women with higher levels of education ${ }^{22}$.

In 1996, there were 14247 respondents to Survey 1 for young women. Of this group, 9689 (68\%) completed Survey 2 four years later when participants were aged 2227 years. Comparison of these women with those who failed to respond to Survey 2 showed no consistent differences in area of residence, education, marital status or self-rated physical or mental health ${ }^{23}$. The analyses reported here are based on responses to Survey 2 , the only survey to include questions about the exclusion of red meat, poultry and fish.

\section{Questionnaire and measures}

Survey 2 included items relating to general health and well-being, health service use and health behaviours. The self-complete postal survey also included questions about demographic characteristics such as area of residence, marital status, educational qualifications and income.
Vegetarian status

Participants were asked 'Do you exclude any of the following food groups from your diet? a) Red meat (beef, lamb, pork); b) Fish; c) Poultry'. Data were self-report: participants were categorised as 'vegetarian' if they reported excluding meat, poultry and fish from their diet; as 'semi-vegetarian' if they reported excluding red meat; and 'non-vegetarian' if they included red meat in their diet.

\section{Lifestyle characteristics}

Questions from previously validated instruments were asked to obtain information on physical activity ${ }^{24}$. Scores were categorised as: 'sedentary' ( $<10$ min per week); 'low' (10 to 150 min per week); 'moderate' (150 to $300 \mathrm{~min}$ per week); and 'high' (300 or more min per week). Total time spent sitting in the last week was based on reported hours spent sitting on a usual weekday and a usual weekend day. Tertiles of sitting time were used to categorise low $(<33 \mathrm{~h})$, moderate $(33$ to $<52 \mathrm{~h})$ and high sitting times $(52 \mathrm{~h} \text { or more })^{23}$. Several questions on smoking behaviour were used to categorise women as 'never-smokers', 'exsmokers' or 'current smokers'. Questions on the frequency and quantity of alcohol consumed were used to define five categories of alcohol consumption: 'non-drinker', 'rarely drinks', 'low-risk drinker', 'risky drinker' and 'high-risk drinker' ${ }^{25}$. Women reported their height and weight, from which BMI was calculated as weight in kilograms divided by the square of height in metres for all non-pregnant women. BMI was categorised as 'underweight' (BMI $<20$ $\mathrm{kg} \mathrm{m}^{-2}$ ), 'healthy weight' (BMI $=20-25 \mathrm{~kg} \mathrm{~m}^{-2}$ ), 'overweight' $\left(\mathrm{BMI}>25-30 \mathrm{~kg} \mathrm{~m}^{-2}\right.$ ) and 'obese' (BMI $>30$ $\mathrm{kg} \mathrm{m}^{-2}$ ) according to the Australian National Health and Medical Research Council classification system ${ }^{26}$.

\section{Health status}

The Medical Outcomes Study Short Form Health Survey (SF-36) was included to measure perceived general health and well-being ${ }^{27}$. Summary scores for physical and mental health (PCS and MCS) were derived from the 36 items of the $\mathrm{SF}-36^{28}$. The summary scores are compared with norms for the reference population (in this case the younger ALSWH cohort), where the population average is set at 50 . Thus a score below 50 indicates worse physical or mental health than the reference population, while a score above 50 indicates better health than the reference population. Self-reported diagnoses were ascertained by the question 'Have you ever been told by a doctor that you have. . .?' followed by a list of diagnoses. Diagnoses of low iron (iron deficiency or anaemia), asthma, depression and anxiety disorder were selected on the basis of their overall prevalence and previous reports of some relationship with vegetarianism ${ }^{15}$. Symptoms were assessed from responses to a question 'In the last 12 months have you had any of the following...?' with response options of 'rarely', 'sometimes' and 'often'. The symptoms included in 
the current analyses were tiredness, allergies, headaches, back pain, menstrual problems, bowel and skin problems, difficulty sleeping, depression and panic attacks or palpitations, with women who responded 'sometimes' or 'often' being categorised as having experienced that symptom. Deliberate self-harm was assessed by an affirmative answer to the question 'In the past 6 months have you ever deliberately hurt yourself or done anything that you knew might have harmed or even killed you?' (yes/no).

\section{Health service use}

Participants were asked how many times they had visited a family doctor or general practitioner for reasons other than pregnancy or contraception and whether they had consulted 'an allied bealth professional (e.g. optician, dentist, physiotherapist, counsellor, etc.)' or 'an "alternative" health practitioner (e.g. naturopath, acupuncturist, berbalist, etc.)' in the last year. The number of prescribed medicines taken in the last four weeks was determined from questions about the number of prescribed medications used 'for your nerves', 'to belp you sleep', 'for depression'; and 'other medication prescribed by a doctor (excluding the oral contraceptive pill)'. Participants were also asked if they were using the oral contraceptive pill. A question about 'other medication bought without a prescription at the chemist, supermarket or bealth food shop' was used to determine the use of non-prescribed medications.

\section{Statistical analysis}

All analyses were conducted using SAS $^{29}$ and were weighted (area-adjusted) to correct for over-sampling of women from rural and remote areas $^{22}$. Means and confidence intervals were calculated for the continuous variables (PCS, MCS and BMI) using the least-squares means option of the generalised linear models procedure of SAS. Differences in proportions for categorical variables (demographic and lifestyle characteristics, health status and health service use) were tested using the chi-square test. For statistically significant variables, post hoc analyses were conducted to determine differences between semi-vegetarians, vegetarians and nonvegetarians. Bonferroni corrections were used to maintain an overall significance level of $0.05^{30}$.

\section{Results}

The response rate to the questions about exclusion of red meat, poultry or fish from the diet was 94\% (9113/9689). After adjustment for the over-sampling of women living in rural and remote areas, we estimate that $87 \%$ of women in this group are non-vegetarian, $10 \%$ are semi-vegetarian (excluded red meat) and 3\% are vegetarian (excluded red meat, poultry and fish)

Demographic and lifestyle characteristics of women in each of the three dietary groups are shown in Table 1.
Vegetarian and semi-vegetarian women were more likely to be living in an urban area and to not be married (see Table 1). Vegetarian women were more likely to have a university degree than semi-vegetarian and non-vegetarian women. Despite this, they were more likely to report lower income than non-vegetarian or semivegetarian women.

In terms of health behaviours, the semi-vegetarian and vegetarian women were more likely to report high levels of physical activity and were more likely to be in the healthy BMI range than non-vegetarians. Mean (95\% confidence interval) for BMI was 23.7 (23.6-23.8), 23.0 (22.7-23.3) and $22.2(21.7-22.7) \mathrm{kg} \mathrm{m}^{-2}$ for nonvegetarian, semi-vegetarian and vegetarian women, respectively. The semi-vegetarians were more likely to be smokers than vegetarian and non-vegetarian women (see Table 1).

Data relating to health status, diagnoses and symptoms are shown in Table 2. Non-vegetarian, semi-vegetarian and vegetarian women did not differ in their self-reported physical health; however, the mental health of nonvegetarians was better than that of either vegetarian group. Overall, diagnoses and symptoms were more commonly reported by vegetarians and semi-vegetarians than by non-vegetarians. This was particularly evident for menstrual symptoms, bowel problems and the diagnoses of low iron, depression and related symptoms. Vegetarians and semi-vegetarians were two to three times more likely to report deliberate self-harm than non-vegetarians (see Table 2). While semi-vegetarians were more likely to report asthma, tiredness and skin problems than nonvegetarians, vegetarians were not. No statistically significant differences in health status, diagnoses or symptoms were found between vegetarians and semi-vegetarians (Table 2).

Data relating to use of health services and medications are shown in Table 3. Despite the differences in diagnoses and symptoms, there were no differences between the non-vegetarians and the vegetarian groups in visits to general practitioners or allied health professionals in the last year (see Table 3). The semi-vegetarian and vegetarian women were, however, more likely to have visited an alternative health practitioner and were more likely to report taking prescription medications for depression. Semi-vegetarians reported taking more prescription and non-prescription medications than non-vegetarians. Compared with non-vegetarians, semi-vegetarians were less likely and vegetarians much less likely to be taking the oral contraceptive pill. No other differences in health service and medication use were found between semi-vegetarians and vegetarians.

\section{Discussion}

Many publications have claimed that vegetarians are healthier than non-vegetarians, as evidenced by their 
Table 1 Demographic and lifestyle characteristics of 22-27-year-old women by vegetarian status

\begin{tabular}{|c|c|c|c|c|}
\hline & $\begin{array}{l}\text { Non-vegetarian } \\
\quad(n=8034)\end{array}$ & $\begin{array}{l}\text { Semi-vegetarian } \\
\quad(n=827)\end{array}$ & $\begin{array}{l}\text { Vegetarian } \\
(n=252)\end{array}$ & $P$-value \\
\hline Urban residence $(\%)^{\star} \dagger$ & 58.8 & 70.7 & 69.8 & $<0.001$ \\
\hline \multicolumn{5}{|l|}{ Marital status $(\%)^{*} \dagger$} \\
\hline Registered marriage & 25.2 & 14.0 & 10.9 & \multirow[t]{3}{*}{$<0.001$} \\
\hline Living as married & 20.2 & 18.5 & 22.7 & \\
\hline Not married & 54.6 & 67.5 & 66.4 & \\
\hline \multicolumn{5}{|l|}{ Educational qualifications (\%)†‡ } \\
\hline Less than Year 12 & 9.7 & 7.0 & 7.1 & \multirow[t]{4}{*}{$<0.001$} \\
\hline Year 12 & 22.5 & 24.3 & 20.3 & \\
\hline Trade/certificate/diploma & 23.4 & 23.5 & 13.6 & \\
\hline University degree & 44.4 & 45.2 & 59.0 & \\
\hline \multicolumn{5}{|l|}{ Annual income $(\%) \dagger \ddagger$} \\
\hline Less than 16000 AUD & 24.2 & 21.5 & 31.4 & \multirow{5}{*}{0.002} \\
\hline $16000-25999$ AUD & 19.8 & 19.5 & 24.6 & \\
\hline $26000-51999$ AUD & 45.6 & 46.9 & 36.0 & \\
\hline 52000 AUD or more & 3.5 & 3.9 & 1.4 & \\
\hline Not classified & 6.9 & 8.2 & 6.6 & \\
\hline \multicolumn{5}{|l|}{ Physical activity in the last week $(\%)^{\star} \dagger$} \\
\hline Sedentary (<10 min per week) & 9.9 & 8.0 & 9.1 & \multirow{4}{*}{$<0.001$} \\
\hline Low $(10$ to $<150$ min per week) & 35.8 & 29.5 & 21.7 & \\
\hline Moderate ( 150 to $<300 \mathrm{~min}$ per week) & 23.8 & 22.5 & 25.4 & \\
\hline High (300 or more min per week) & 30.5 & 40.0 & 43.8 & \\
\hline \multicolumn{5}{|l|}{ Total hours sitting in the last week (\%) } \\
\hline Low $(<33 \mathrm{~h})$ & 30.6 & 31.2 & 25.8 & \multirow[t]{3}{*}{0.520} \\
\hline Moderate $(33$ to $<52 \mathrm{~h})$ & 32.7 & 31.7 & 35.1 & \\
\hline High ( $52 \mathrm{~h}$ or more) & 36.7 & 37.1 & 39.1 & \\
\hline \multicolumn{5}{|l|}{ Body mass index $(\%)^{*} \dagger$} \\
\hline Underweight $\left(<20 \mathrm{kgm}^{-2}\right)$ & 20.6 & 24.1 & 25.3 & \multirow[t]{4}{*}{$<0.001$} \\
\hline Healthy weight $\left(20-25 \mathrm{~kg} \mathrm{~m}^{-2}\right)$ & 50.0 & 53.0 & 59.0 & \\
\hline Overweight $\left(>25-30 \mathrm{~kg} \mathrm{~m}^{-2}\right)^{\prime}$ & 19.1 & 15.4 & 12.4 & \\
\hline Obese $\left(>30 \mathrm{~kg} \mathrm{~m}^{-2}\right)$ & 10.3 & 7.4 & 3.4 & \\
\hline \multicolumn{5}{|l|}{ Smoking status $(\%)^{*} \dagger$} \\
\hline Non-smoker & 59.7 & 55.4 & 62.7 & \multirow[t]{3}{*}{0.008} \\
\hline Ex-smoker & 14.2 & 13.3 & 15.5 & \\
\hline Current smoker & 26.1 & 31.3 & 21.8 & \\
\hline \multicolumn{5}{|l|}{ Alcohol consumption (\%) } \\
\hline Non-drinker & 8.8 & 8.6 & 11.3 & \multirow[t]{5}{*}{0.146} \\
\hline Rarely drinks & 28.0 & 24.2 & 27.3 & \\
\hline Low-risk drinker & 59.8 & 62.5 & 58.7 & \\
\hline Risky drinker & 3.1 & 4.3 & 2.7 & \\
\hline High-risk drinker & 0.3 & 0.4 & 0 & \\
\hline
\end{tabular}

AUD - Australian dollars.

With the exception of urban residence, percentages are weighted to allow for over-sampling of women living in rural and remote areas. Actual numbers of non-vegetarian, semi-vegetarian and vegetarian women differ due to small amounts of missing data $(0-3.6 \%)$ for all variables other than body mass index (7.9\% missing).

${ }^{*}$ Non-vegetarians significantly different from semi-vegetarians

†Non-vegetarians significantly different from vegetarians.

$\ddagger$ Semi-vegetarians significantly different from vegetarians.

greater longevity and lower morbidity ${ }^{1,2,5}$. Most of these studies have, however, focused on specific vegetarian groups such as Seventh Day Adventists, who may have additional 'healthy lifestyle' behaviours which impact on their health. In contrast, the results of the present study, which are taken from a sample that was originally randomly selected from the entire population of young Australian women, provide a mixed picture of the health of women who avoid red meat or who are vegetarian. Although their physical health was good, there was a clear indication in this study that both vegetarian and semivegetarian women experienced mental health problems (including depression, anxiety and sleeplessness), menstrual problems and low iron. They also reported taking more prescription medications for depression.
In this study of 22-27-year-old Australian women, the estimated prevalence of vegetarianism was 3\%, with a further 10\% of women excluding red meat from their diet. Our estimated prevalence of 'vegetarianism' is lower than the prevalence of 6\% for 19-24-year-old and 5\% for 2544-year-old Australian women reported in the 1995 Australian National Nutritional Survey; a finding which may reflect the different definitions and sampling frames used $^{20,21}$. The prevalence of $10 \%$ of women excluding red meat is similar to that reported for girls attending secondary school in South Australia ${ }^{20}$. In this study the vegetarians and semi-vegetarians were more likely to be single and the vegetarians were more highly educated; characteristics which have been reported in previous studies of vegetarians 9,19 . The bias towards more 
Table 2 Physical and mental well-being, diagnoses and symptoms reported by women in each dietary group

\begin{tabular}{|c|c|c|c|c|}
\hline & $\begin{array}{l}\text { Non-vegetarian } \\
\quad(n=8034)\end{array}$ & $\begin{array}{l}\text { Semi-vegetarian } \\
\quad(n=827)\end{array}$ & $\begin{array}{l}\text { Vegetarian } \\
(n=252)\end{array}$ & $P$-value \\
\hline $\begin{array}{l}\text { Physical Component Summary score, mean } \\
\text { (95\% confidence interval) }\end{array}$ & $50.1(49.8-50.3)$ & $49.7(49.0-50.4)$ & $50.8(49.5-52.1)$ & 0.671 \\
\hline $\begin{array}{l}\text { Mental Component Summary score, mean } \\
(95 \% \text { conference interval })^{*} \dagger\end{array}$ & $50.5(50.3-50.7)$ & $48.4(47.6-49.1)$ & $47.6(46.3-49.0)$ & $<0.001$ \\
\hline \multicolumn{5}{|l|}{ Ever diagnosed (\%) with } \\
\hline Low iron, iron deficiency or anaemia* $\dagger$ & 25.5 & 38.9 & 42.6 & $<0.001$ \\
\hline Asthma* $^{*}$ & 22.7 & 27.0 & 21.7 & 0.016 \\
\hline Depression $^{\star} \dagger$ & 13.4 & 20.1 & 20.3 & $<0.001$ \\
\hline Anxiety disorder* $\dagger$ & 5.8 & 8.4 & 10.1 & $<0.001$ \\
\hline \multicolumn{5}{|l|}{$\begin{array}{l}\text { Symptoms experienced 'sometimes' or 'often' } \\
\text { in the last year (\%) }\end{array}$} \\
\hline Severe tiredness* & 42.6 & 48.5 & 44.9 & 0.003 \\
\hline Difficulty sleeping $^{*} \dagger$ & 27.2 & 35.3 & 33.5 & $<0.001$ \\
\hline Depression* $^{*}$ & 19.5 & 29.4 & 29.1 & $<0.001$ \\
\hline Panic attacks or palpitations* & 16.0 & 19.8 & 18.3 & 0.012 \\
\hline Deliberate self-harm$†$ & 3.1 & 7.3 & 10.0 & $<0.001$ \\
\hline Premenstrual tension* $\dagger$ & 34.0 & 40.0 & 42.6 & $<0.001$ \\
\hline Irregular periods* $\dagger$ & 18.7 & 25.0 & 27.5 & $<0.001$ \\
\hline Heavy periods* & 15.5 & 18.9 & 18.0 & 0.022 \\
\hline Severe period pain ${ }^{\star} \dagger$ & 24.4 & 31.6 & 32.4 & $<0.001$ \\
\hline Back pain & 40.4 & 41.0 & 38.6 & 0.789 \\
\hline Constipation or other bowel problems ${ }^{*} \dagger$ & 22.7 & 27.5 & 29.1 & $<0.001$ \\
\hline Headaches/migraines & 58.7 & 55.7 & 53.3 & 0.053 \\
\hline Skin problems ${ }^{\star}$ & 24.0 & 30.6 & 27.6 & $<0.001$ \\
\hline Allergies, hay fever, sinusitis & 45.7 & 45.2 & 42.3 & 0.525 \\
\hline
\end{tabular}

Percentages are weighted to allow for over-sampling of women living in rural and remote areas. Actual numbers of non-vegetarian, semi-vegetarian and vegetarian women differ due to small amounts of missing data $(0.1-2.8 \%)$.

${ }^{*}$ Non-vegetarians significantly different from semi-vegetarians.

† Non-vegetarians significantly different from vegetarians.

Table 3 Health service and medication use by women in each of the dietary groups

\begin{tabular}{|c|c|c|c|c|}
\hline & $\begin{array}{l}\text { Non-vegetarian } \\
\quad(n=8034)\end{array}$ & $\begin{array}{l}\text { Semi-vegetarian } \\
\quad(n=827)\end{array}$ & $\begin{array}{l}\text { Vegetarian } \\
(n=252)\end{array}$ & $P$-value \\
\hline \multicolumn{5}{|l|}{ Number of visits to general practitioner in the last year (\%) } \\
\hline None & 14.3 & 15.1 & 14.5 & \multirow[t]{4}{*}{0.796} \\
\hline One to two & 33.7 & 32.5 & 32.5 & \\
\hline Three to four & 27.4 & 26.9 & 24.7 & \\
\hline Five or more & 24.7 & 25.5 & 28.3 & \\
\hline Consulted an allied health professional in the last year (\%) & 58.5 & 59.6 & 60.9 & 0.630 \\
\hline Consulted an alternative health practitioner in last year $(\%)^{*} \dagger$ & 15.3 & 26.2 & 24.7 & $<0.001$ \\
\hline \multicolumn{5}{|l|}{ Number of prescription medications in last four weeks $(\%)^{*}$} \\
\hline None & 71.4 & 64.7 & 70.7 & \multirow[t]{3}{*}{$<0.001$} \\
\hline One to two & 22.9 & 27.0 & 22.5 & \\
\hline Three or more & 5.7 & 8.3 & 6.8 & \\
\hline \multicolumn{5}{|l|}{ Taken prescription medications in the last four weeks (\%) } \\
\hline For nerves* & 1.7 & 2.9 & 2.2 & 0.046 \\
\hline To sleep & 2.6 & 4.1 & 3.2 & 0.070 \\
\hline For depression* $\dagger$ & 4.2 & 6.4 & 8.0 & $<0.001$ \\
\hline For other reasons excluding contraception ${ }^{*}$ & 24.8 & 29.5 & 22.4 & 0.007 \\
\hline Currently taking the oral contraceptive pill $(\%)^{*} \ddagger$ & 56.2 & 51.2 & 37.1 & $<0.001$ \\
\hline Taken non-prescription medication in the last four weeks $(\%)^{\star}$ & 50.4 & 56.0 & 51.3 & 0.007 \\
\hline
\end{tabular}

Percentages are weighted to allow for over-sampling of women living in rural and remote areas. Actual numbers of non-vegetarian, semi-vegetarian and vegetarian women differ due to small amounts of missing data $(0-1.3 \%)$.

*Non-vegetarians significantly different from semi-vegetarians.

$\dagger$ Non-vegetarians significantly different from vegetarians.

$\ddagger$ Semi-vegetarians significantly different from vegetarians.

educated, single women in this study may mean that the prevalence of 'vegetarianism' has been overestimated although this seems unlikely given the similarities to estimates obtained from other studies.

In this large study of randomly selected young women, no differences were found in alcohol consumption by vegetarians, semi-vegetarians and non-vegetarians, which is consistent with the findings from studies of adolescents $^{6,7}$. In contrast to these studies, smoking and physical activity differed by vegetarian status. Vegetarian women were less likely to smoke than the semi-vegetarians and both the semi-vegetarians and vegetarians were more 
likely to report high levels of physical activity. The proportion of women in these two groups who reported doing more than 150 min of activity per week was much higher than current population estimates for young women $^{31}$. Semi-vegetarian and vegetarian women were also more likely to be in the healthy BMI range.

These data suggest that the mental health of vegetarian and semi-vegetarian women is considerably poorer than that of non-vegetarian women in the same age group. The mental health scores for semi-vegetarians and vegetarians were significantly lower than those for non-vegetarians. Women in these groups also reported more depressive symptoms and deliberate self-harm, findings which are consistent with studies of adolescents ${ }^{6-8}$. The vegetarians and semi-vegetarians were also more likely to be taking medication 'for depression'. Although our findings are suggestive of a link between the avoidance of red meat and poorer mental health, it is not possible to state from these cross-sectional data whether any specific dietary deficiencies are the cause of these differences in mental health or the direction of any relationship between these variables.

In this study of young women, vegetarians and semivegetarians reported more menstrual symptoms (irregularity, premenstrual tension and severe period pain) than non-vegetarian women. To our knowledge, this is the first large population-based study to show these differences. Although previous studies have reported menstrual irregularity in vegetarians, these have been restricted to small selected groups ${ }^{16-18}$. While recent research suggests that there may be links between iron status, menstrual problems, tiredness and cognitive function ${ }^{15,32}$, there is clearly a need for more population studies of the interrelationships between diet, activity, BMI and menstrual problems, and their impact on tiredness and mental health.

The higher prevalence of constipation among vegetarian and semi-vegetarian women was unexpected and contradicted the findings of previous studies ${ }^{1,3}$. However, constipation is a well-recognised symptom of people with eating disorders ${ }^{33}$, a trait more likely to be displayed among young vegetarians than non-vegetarians. We cannot exclude the possibility that some vegetarians in this study had eating disorders and thus would be more likely to experience constipation.

Previous studies have reported that vegetarians use health services and medications less than non-vegetarians, but that vegetarians are more willing to try alternative therapies ${ }^{13,19}$. The results presented here confirm that vegetarian and semi-vegetarian young women are more likely to visit alternative health practitioners. Previous studies have suggested that alternative services and treatments are more commonly used by people who report poorer health, have a number of health problems, or when conventional health services and treatments have proved ineffective ${ }^{34}$. However, in general, these young women did not have many serious health problems, and their use of alternative health services may simply reflect a real difference in perception of the benefits of different forms of health care.

The main limitation of the present study is that all data are self-reported. Vegetarian status was defined purely on self-reported exclusion of red meat, poultry and fish. Dietary intake was not assessed and therefore vegetarian status could not be verified. Similarly, diagnoses and symptoms were not verified from medical records. However, various studies have investigated self-reported medical history and concluded there was accurate recall in well-defined chronic conditions ${ }^{35,36}$. Furthermore, the consistency of mental health reports across a range of measures adds weight to this argument.

Third, this is a cross-sectional analysis, so that no inferences about causation can be made. For example, women with poorer health may have changed to a vegetarian diet or vice versa. Despite these limitations, this study provides the first national data on the health and vegetarian status of young women.

In conclusion, vegetarian and semi-vegetarian young women appear to be different from non-vegetarians in terms of healthier body weight and physical activity, but less healthy in terms of smoking tobacco (semivegetarians). The data are strongly suggestive of poorer mental health among non meat-eaters, as evidenced by several indicators, including the SF-36, reporting of diagnoses and symptoms, and greater use of medications for mental health problems. Vegetarian and semivegetarian women also report more menstrual symptoms, including irregular periods, severe period pain and premenstrual tension. Future studies of this cohort will attempt to untangle the relationships between meat-eating and some of the health problems reported here.

\section{Acknowledgements}

The Australian Longitudinal Study on Women's Health, which was conceived and developed by groups of interdisciplinary researchers at the Universities of Newcastle and Queensland, is funded by the Australian Commonwealth Department of Health and Ageing. We thank all the participants for their valuable contribution to the project.

\section{References}

1 Key TJ, Davey GK, Appleby PN. Health benefits of a vegetarian diet. Proceedings of the Nutrition Society 1999; 58: $271-5$.

2 Appleby PN, Thorogood M, Mann JI, Key TJ. The Oxford Vegetarian Study: an overview. American Journal of Clinical Nutrition 1999; 70: 525S-31S.

3 Dwyer JT. Health aspects of vegetarian diets. American Journal of Clinical Nutrition 1988; 48: 712S-38S.

4 Fraser GE. Associations between diet and cancer, ischemic heart disease, and all-cause mortality in non-Hispanic white California Seventh-day Adventists. American Journal of Clinical Nutrition 1999; 70: 532S-8S. 
5 Singh PN, Sabate J, Fraser GE. Does low meat consumption increase life expectancy in humans? American Journal of Clinical Nutrition 2003; 78: 526S-32S.

6 Larsson CL, Klock KS, Nordrehaug Astrom A, Haugejorden O, Johansson G. Lifestyle-related characteristics of young low-meat consumers and omnivores in Sweden and Norway. Journal of Adolescent Health 2002; 31: 190-8.

7 Neumark-Sztainer D, Story M, Resnick MD, Blum RW. Adolescent vegetarians. A behavioral profile of a schoolbased population in Minnesota. Archives of Pediatrics $\varepsilon$ Adolescent Medicine 1997; 151: 833-8.

8 Perry CL, McGuire MT, Neumark-Sztainer D, Story M. Characteristics of vegetarian adolescents in a multiethnic urban population. Journal of Adolescent Health 2001; 29 406-16.

9 Davey GK, Spencer EA, Appleby PN, Allen NE, Knox KH, Key TJ. EPIC-Oxford: lifestyle characteristics and nutrient intakes in a cohort of 33883 meat-eaters and 31546 non meat-eaters in the UK. Public Health Nutrition 2003; 6: 259-69.

10 Perry CL, McGuire MT, Neumark-Sztainer D, Story M. Adolescent vegetarians: how well do their dietary patterns meet the healthy people 2010 objectives? Archives of Pediatrics \& Adolescent Medicine 2002; 156: 431-7.

11 Barr SI, Broughton TM. Relative weight, weight loss efforts and nutrient intakes among health-conscious vegetarian, past vegetarian and nonvegetarian women ages 18 to 50 . Journal of the American College of Nutrition 2000; 19: $781-8$.

12 Slattery ML, Jacobs DR Jr, Hilner JE, Caan BJ, Van Horn L, Bragg $\mathrm{C}$, et al. Meat consumption and its associations with other diet and health factors in young adults: the CARDIA study. American Journal of Clinical Nutrition 1991; 54: $930-5$.

13 Freeland-Graves JH, Greninger SA, Graves GR, Young RK. Health practices, attitudes, and beliefs of vegetarians and nonvegetarians. Journal of the American Dietetic Association 1986; 86: 913-8.

14 Freeland-Graves JH, Greninger SA, Young RK. A demographic and social profile of age- and sex-matched vegetarians and nonvegetarians. Journal of the American Dietetic Association 1986; 86: 907-13.

15 Patterson AJ, Brown WJ, Roberts DC. Dietary and lifestyle factors influencing iron stores in Australian women: an examination of the role of bio-available dietary iron. Australian Journal of Nutrition and Dietetics 2001; 58: 107-13.

16 Griffith J, Omar H. Association between vegetarian diet and menstrual problems in young women: a case presentation and brief review. Journal of Pediatric and Adolescent Gynecology 2003; 16: 319-23.

17 Barr SI. Vegetarianism and menstrual cycle disturbances: is there an association? American Journal of Clinical Nutrition 1999; 70: 549S-54S.

18 Pedersen AB, Bartholomew MJ, Dolence LA, Aljadir LP, Netteburg KL, Lloyd T. Menstrual differences due to vegetarian and nonvegetarian diets. American Journal of Clinical Nutrition 1991; 53: 879-85.
19 Knutsen SF. Lifestyle and the use of health services. American Journal of Clinical Nutrition 1994; 59: 1171S-5S.

20 Worsley A, Skrzypiec G. Teenage vegetarianism: prevalence, social and cognitive contexts. Appetite 1998; 30: 151-70.

21 Australian Bureau of Statistics. National Nutrition Survey: Selected Highlights, Australia. Catalogue No. 4802.0. Canberra: Australian Government Publishing Service, 1997.

22 Brown WJ, Dobson AJ, Bryson L, Byles JE. Women's Health Australia: on the progress of the main cohort studies. Journal of Women's Health \& Gender-based Medicine 1999; 8: 681-8.

23 Ball K, Brown W, Crawford D. Who does not gain weight? Prevalence and predictors of weight maintenance in young women. International Journal of Obesity and Related Metabolic Disorders 2002; 26: 1570-8.

24 Brown WJ, Bauman AE. Comparison of estimates of population levels of physical activity using two measures. Australian and New Zealand Journal of Public Health 2000; 24: $520-5$.

25 National Health and Medical Research Council. Australian Alcohol Guidelines: Health Risks and Benefits. Canberra: Australian Government Publishing Service, 2001.

26 National Health and Medical Research Council. Acting on Australia's Weight: A Strategic Plan for the Prevention of Overweight and Obesity. Canberra: Australian Government Publishing Service, 1997.

27 Ware J, Kosinski M, Keller S. SF-36 Physical and Mental Health Summary Scales: A User's Manual. Boston, MA: The Health Institute, New England Medical Centre, 1994.

28 Mishra G, Schofield MJ. Norms for the physical and mental health component summary scores of the SF-36 for young, middle-aged and older Australian women. Quality of Life Research 1998; 7: 215-20.

29 SAS Institute Inc. SAS/STAT User's Guide, Version 8. Cary, NC: SAS Institute Inc., 1999.

30 Netter J, Kutner MH, Nachtsheim CJ, Wasserman W. Applied Linear Statistical Models, 4th ed. Chicago, IL: Irwin, 1996.

31 Armstrong T, Bauman A, Davies J. Physical Activity Patterns of Australian Adults. Results of the 1999 National Physical Activity Survey. Canberra: Australian Institute of Health of Welfare, 2000

32 Patterson AJ, Brown WJ, Powers JR, Roberts DC. Iron deficiency, general health and fatigue: results from the Australian Longitudinal Study on Women's Health. Quality of Life Research 2000; 9: 491-7.

33 Boyd C, Abraham S, Kellow J. Psychological features are important predictors of functional gastrointestinal disorders in patients with eating disorders. Scandinavian Journal of Gastroenterology 2005; 40: 929-35.

34 Wiles J, Rosenberg MW. 'Gentle caring experience'. Seeking alternative health care in Canada. Health \& Place 2001; 7: 209-24.

35 Kehoe R, Wu SY, Leske MC, Chylack LT Jr. Comparing selfreported and physician-reported medical history. American Journal of Epidemiology 1994; 139: 813-8.

36 Colditz GA, Stampfer MJ, Willett WC, Stason WB, Rosner B, Hennekens $\mathrm{CH}$, et al. Reproducibility and validity of selfreported menopausal status in a prospective cohort study. American Journal of Epidemiology 1987; 126: 319-25. 